\title{
Research Article \\ Study on the Catastrophic Evolution of Tianshan Road Slope under the Freeze-Thaw Cycles
}

\author{
Luqi Wang $\mathbb{D}$, Yibing Zhang, Jian Guo, Qiang Ou, Songlin Liu, and Lin Wang $\mathbb{D}$ \\ School of Civil Engineering, Chongqing University, Chongqing 400045, China \\ Correspondence should be addressed to Lin Wang; sdxywanglin@cqu.edu.cn
}

Received 24 August 2021; Accepted 7 September 2021; Published 4 October 2021

Academic Editor: Yu Wang

Copyright (c) 2021 Luqi Wang et al. This is an open access article distributed under the Creative Commons Attribution License, which permits unrestricted use, distribution, and reproduction in any medium, provided the original work is properly cited.

\begin{abstract}
The maximum temperature difference of Tianshan Road can reach $77.4^{\circ} \mathrm{C}$ in a year. Under such complex mechanical environment, the mechanical properties of rock mass and structural planes will change significantly as the increase of freezethaw cycles (FTC). Consequently, the FTC has become a key factor in the instability and failure of rocky slopes along the Tianshan Road. In this paper, the progressive deformation of rocky slopes and sudden failure process after critical instability were studied through the FTC tests of rock mass and structural planes, discrete element method, and theoretical analysis. The results show that the structural planes and internal microcracks of the rock mass expand under the action of the FTC, causing a gradual decrease in the stability of the slope. The dynamic collapse of the rocky slope has a certain degree of randomness caused by the spatial distribution of structural planes and the interaction between the rock fragments. Due to the limitation of the slipping space and the tilt angle of the trailing edge of the slope, long-distance migration did not occur, and the in situ accumulation of the slope was obvious after failure. The analysis method in this paper can provide an important reference for guiding the catastrophe mechanism analysis and protection of engineering slopes in cold regions.
\end{abstract}

\section{Introduction}

The Tianshan Mountains are composed of more than 20 parallel high-steep mountains [1]. As a result, many highaltitude areas do not melt all year round [2]. The Tianshan Road is a major traffic artery that traverses the northern, central, and southern parts of the Tianshan Mountains and connects southern Xinjiang with northern Xinjiang. Therefore, its geographic location is very important ([3]; Figure 1).

The Tianshan Road has a total length of $537 \mathrm{~km}$, most of which is through the alpine mountains above $2000 \mathrm{~m}$, and the geological conditions of the entire line are extremely complicated. It starts at Dushanzi and ends at Kuche; the eastern part is connected to the Bayinbulak grassland, and the western part is connected to the Tangbula grassland. Specifically, it passed through Bingdaban at an altitude of more than $4000 \mathrm{~m}$ three times. The Tianshan Road has almost all the geological disasters that can occur on the world's highways, such as collapses, landslides, mudslides, frozen soil, and avalanches.
The study area can be characteristic of complex lithological changes, high-steep slopes, intense unloading, and multiple cracks. Furthermore, the mechanical characteristics of rocky slope change significantly as the increase of the freeze-thaw cycles (FTC), which has become the dominant factor of rocky slope failure [4]. Once the deformation and instability of road slope occur, the operation of highway engineering will be seriously affected. As for these mechanical environments, indoor rock mechanics tests $[5,6]$, similar model tests [7], numerical simulations $[8,9]$, in situ monitoring $[10,11]$, and failure mechanisms $[12-14]$ are used to study the evolution trend of rock mass. However, there are still significant gaps between the existing research methods and the research motivation to effectively reveal the catastrophic evolution of rocky slopes under the FTC, especially in the changing mechanical state and the collapse process after the critical state.

A typical rocky slope along the Tianshan Road was taken as a research object in this paper. Its progressive deformation and sudden failure process were studied through the 

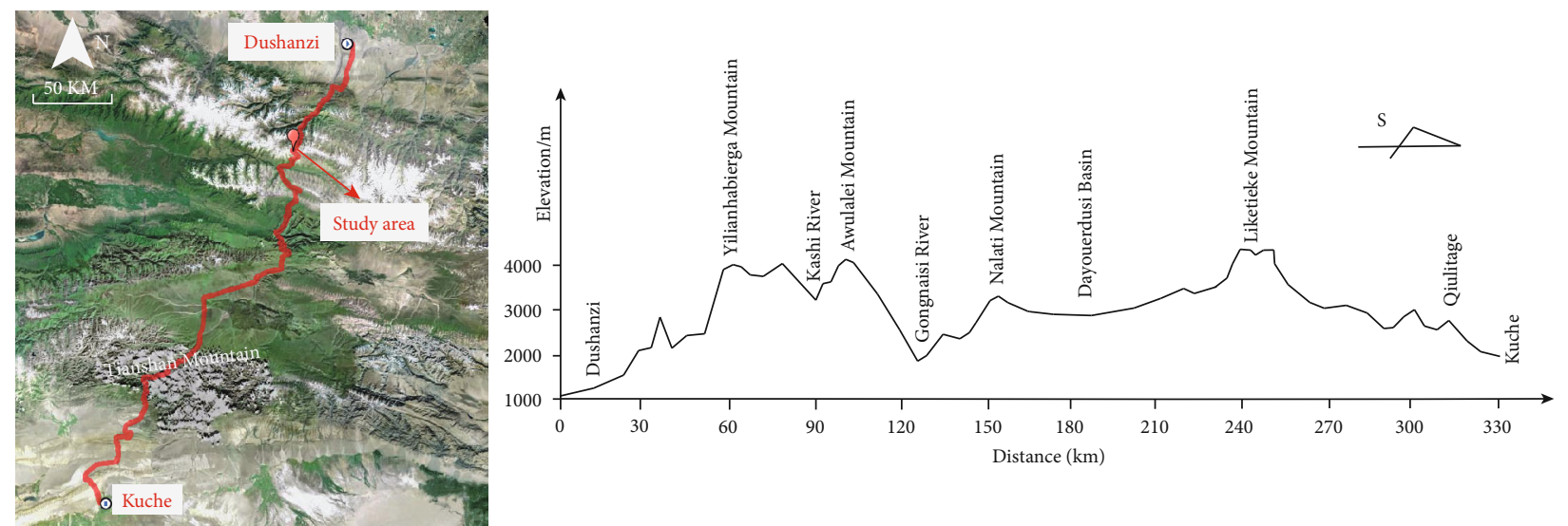

Figure 1: General situation of the Tianshan Road.

FTC test results of rock mass and structural planes, discrete element methods (DEM), and theoretical analysis. These analysis methods can provide important references for guiding the evolution trend and protection of engineering slopes in cold regions.

\section{Study Area}

Through the comparative analysis of the high- and lowtemperature climate along the Tianshan Road, it can be found that the maximum temperature difference between day and night can reach about $45^{\circ} \mathrm{C}$. And the maximum temperature difference in different seasons of the year can reach $77.4^{\circ} \mathrm{C}$, of which the extreme maximum temperature is $41.8^{\circ} \mathrm{C}$ in the Wusu section in the northern part of the study area, and the extreme minimum temperature is $-48.1^{\circ} \mathrm{C}$ in the Bayinbulak area. Due to intense ultraviolet radiation, the surface temperature of the rocky slope is about $12^{\circ} \mathrm{C}$ higher than the expected temperature. Under this extreme climate, the rocky slopes are affected by the high temperature stress, ice cleavage force, and frost heave and thawing shrinkage [15].

In the study area, the terrain is higher in the west and lower in the east, and the altitude is between $2000 \mathrm{~m}$ and $5000 \mathrm{~m}$. Caused by the subduction and compression of the Indian plate to the Eurasian plate, the topography of the mountain crisscross basin is formed. Meanwhile, many glaciers are developed in high-altitude areas along the Tianshan Road. And due to the deep cutting of the valleys, the terrain is undulating, and the natural conditions are harsh.

\section{Engineering Geologic Conditions}

3.1. Topography. The study area is the alpine valley of the North Tianshan Mountains, specifically on the southern slope of Hashelekandaban. The slope height is about $25 \sim 30 \mathrm{~m}$, and the average slope is about $75^{\circ}$. This section is convex and developed in the conglomerate. The leading edge of the slope is the Kuitun River that is about $10 \sim 15 \mathrm{~m}$ wide and about $80 \mathrm{~m}$ away from the road.

3.2. Formation Lithology and Geological Structures. The stratigraphy of the study area is relatively simple, mainly outcropping the Quaternary and the Middle Carboniferous strata. Among them, the Quaternary deposits are distributed above the Kuitun River. It is a mainly fragmented conglomerate with a particle size of $5 \sim 15 \mathrm{~cm}$. The Carboniferous Middle System belongs to the Bayingou Formation in the Yilianhaergabishan district, and the lithology is sandstone. A small fault, about $1 \mathrm{~km}$ south of the study area, is derived from a regional structure.

3.3. Earthquake and Neotectonic Movement. The study area is located near the North Tianshan seismic belt, which spreads in the east-west direction, starting from the east of Barkol and extending westward to the piedmont of the North Tianshan Mountains. The thrust-wrinkle active zone in this area is related to earthquakes. And the earthquake occurrence scope is distributed in an elliptical shape, with features of low occurrence frequency, high intensity, and concentrated time distribution.

3.4. Hydrogeological Conditions. The formation, occurrence, and migration of groundwater are dominated by climatic conditions, topography, stratum lithology, and geological structure. Rainfall and glacier snowmelt are the main supplies of groundwater. Groundwater discharges to rivers through runoff from structure zones or fracture zones. The annual rainfall in the area ranges from $250 \mathrm{~mm}$ to $500 \mathrm{~mm}$. Except for a small amount of evaporation, the rest rainfall is supplied to groundwater and rivers. Fracture water of detrital rocks is the main type of groundwater. Meanwhile, the tuffaceous sandstone is the main aquifer.

3.5. Climate. Through analysis of weather station data in the study area, the extreme cold weather in winter occurs in January, with an average temperature of $-9.0^{\circ} \mathrm{C}$. The maximum thickness of snow can reach $60 \sim 150 \mathrm{~cm}$, and the maximum melting thickness of seasonally frozen soil is $80 \mathrm{~cm}$. The study area surfers the most severe snow damage in winter along the Tianshan Road. Meanwhile, the extreme high-temperature weather of summer occurs in July, with an average temperature of $22.0^{\circ} \mathrm{C}$. The annual precipitation ranges from $250 \mathrm{~mm}$ to $500 \mathrm{~mm}$. The spring and summer are the seasons with heavy rains, accounting for 65 to $80 \%$ of the annual precipitation. 


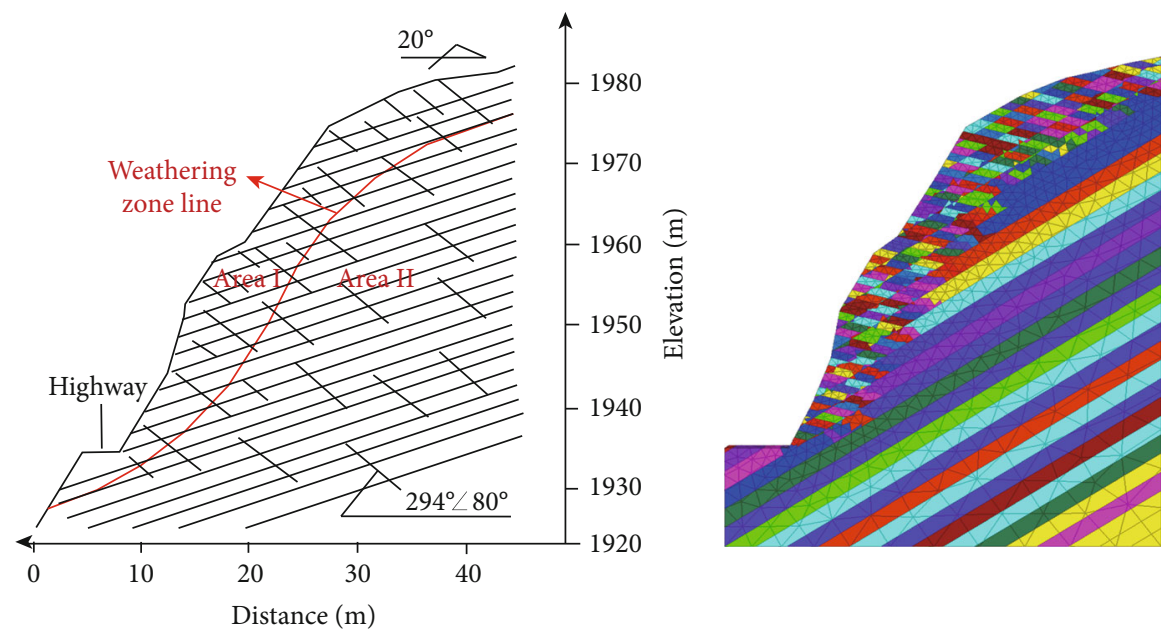

FIGURE 2: The typical section applied in numerical calculations.

TABle 1: Parameters of materials in freeze-thaw area (area I).

\begin{tabular}{|c|c|c|c|c|c|}
\hline \multirow{2}{*}{ Material } & \multirow{2}{*}{ Parameters } & \multicolumn{4}{|c|}{ Time of the freeze-thaw cycles } \\
\hline & & 0 & 15 & 30 & 50 \\
\hline \multirow{6}{*}{ Rock mass } & Density $\left(\mathrm{kg} / \mathrm{m}^{3}\right)$ & 2600 & 2626 & 2678 & 2704 \\
\hline & Volume modulus (GPa) & 5.9 & 3.1 & 2.8 & 2.6 \\
\hline & Shear modulus (GPa) & 5.1 & 2.9 & 2.6 & 2.4 \\
\hline & Cohesion $(\mathrm{MPa})$ & 6.2 & 5.3 & 4.7 & 4.2 \\
\hline & Internal friction angle $\left(^{\circ}\right)$ & 48 & 41 & 36 & 32 \\
\hline & Tensile strength (MPa) & 3.2 & 2.7 & 2.4 & 2.2 \\
\hline \multirow{4}{*}{ Layer } & Normal stiffness (GPa) & 13.2 & 12.6 & 12.2 & 11.9 \\
\hline & Shear stiffness (GPa) & 11.6 & 11.0 & 10.6 & 10.3 \\
\hline & Cohesion $(\mathrm{kPa})$ & 86 & 56 & 50 & 43 \\
\hline & Internal friction angle $\left({ }^{\circ}\right)$ & 42 & 38 & 35 & 34 \\
\hline \multirow{4}{*}{ Structural planes } & Normal stiffness (GPa) & 11.3 & 10.7 & 10.3 & 10.0 \\
\hline & Shear stiffness (GPa) & 0.94 & 0.88 & 0.84 & 0.81 \\
\hline & Cohesion $(\mathrm{kPa})$ & 82 & 53 & 47 & 41 \\
\hline & Internal friction angle $\left({ }^{\circ}\right)$ & 40 & 36 & 33 & 31 \\
\hline
\end{tabular}

TABLE 2: Parameters of materials in nonfreeze-thaw area (area II).

\begin{tabular}{|c|c|c|c|c|c|c|}
\hline Parameters & $\begin{array}{l}\text { Density } \\
\left(\mathrm{kg} / \mathrm{m}^{3}\right)\end{array}$ & $\begin{array}{c}\text { Volume } \\
\text { modulus }(\mathrm{GPa})\end{array}$ & $\begin{array}{l}\text { Shear modulus } \\
(\mathrm{GPa})\end{array}$ & Cohesion $(\mathrm{kPa})$ & $\begin{array}{c}\text { Internal friction } \\
\text { angle }\left({ }^{\circ}\right)\end{array}$ & $\begin{array}{c}\text { Tensile } \\
\text { strength }(\mathrm{MPa})\end{array}$ \\
\hline Rock mass & 2750 & 6.2 & 5.4 & 7.6 & 52 & 3.9 \\
\hline Parameters & $\begin{array}{c}\text { Normal } \\
\text { stiffness }(\mathrm{GPa})\end{array}$ & $\begin{array}{l}\text { Shear stiffness } \\
(\mathrm{GPa})\end{array}$ & Cohesion $(\mathrm{kPa})$ & $\begin{array}{c}\text { Internal friction } \\
\text { angle }\left({ }^{\circ}\right)\end{array}$ & $\begin{array}{l}\text { Tensile strength } \\
(\mathrm{MPa})\end{array}$ & l \\
\hline Layer & 18.2 & 13.6 & 180 & 45 & 1.2 & I \\
\hline Structural planes & 16.4 & 11.3 & 160 & 42 & 0.8 & I \\
\hline
\end{tabular}

\section{Structure and Stability Factors of the Typical Slope}

The rock stratum $\left(180^{\circ} \angle 35^{\circ}\right)$ of the typical slope is the medium-thick layered sandstone. The primary structural planes $\left(294^{\circ} \angle 80^{\circ}\right)$ have a spacing of about $1 \mathrm{~m}$, an opening of $5 \mathrm{~mm}$, straight and smooth, no fillings, and an extension length over $10 \mathrm{~m}$. The rock mass is divided into approximately $1 \mathrm{~m} \times 1 \mathrm{~m} \times 0.5 \mathrm{~m}$, and the linear fissure rate is $55.1 \%$. The shape of the slope is convex, without the influence of groundwater. Due to the excavation and blasting caused the unloading and rebound of the rock mass, this 


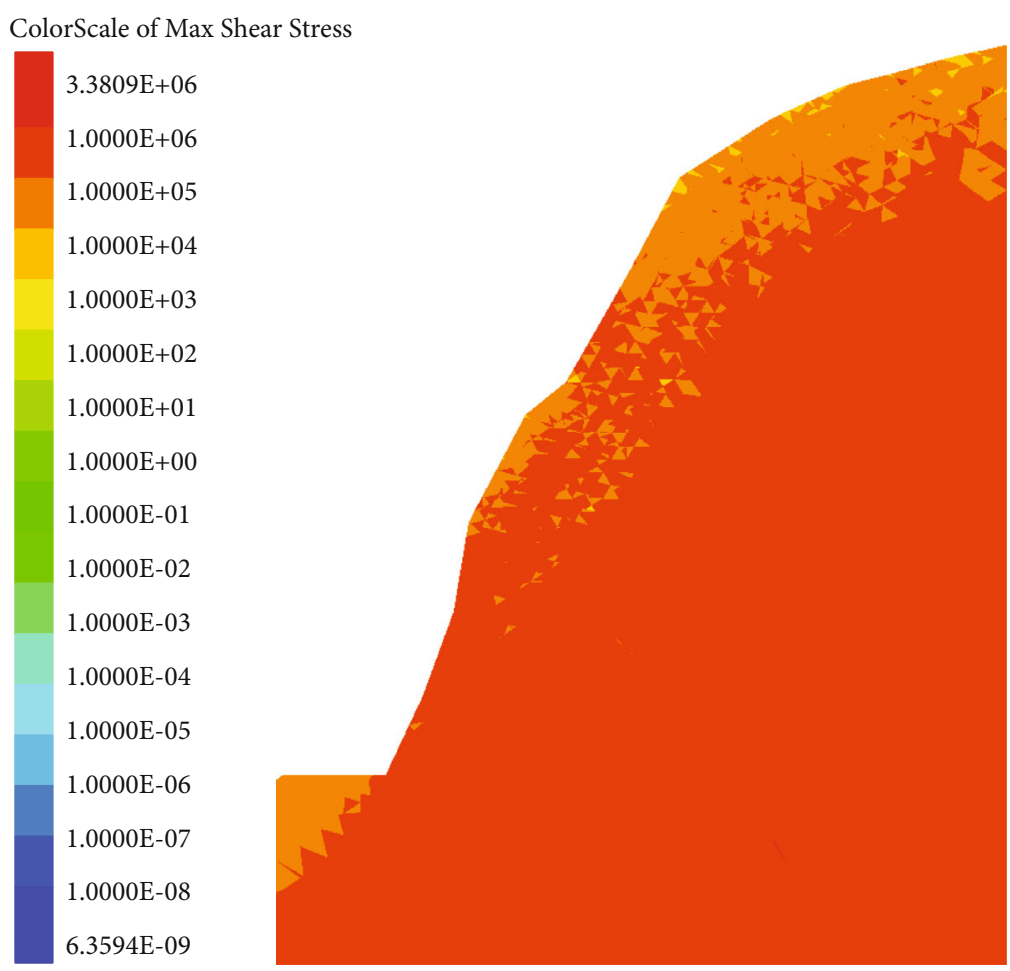

(a) 0 times

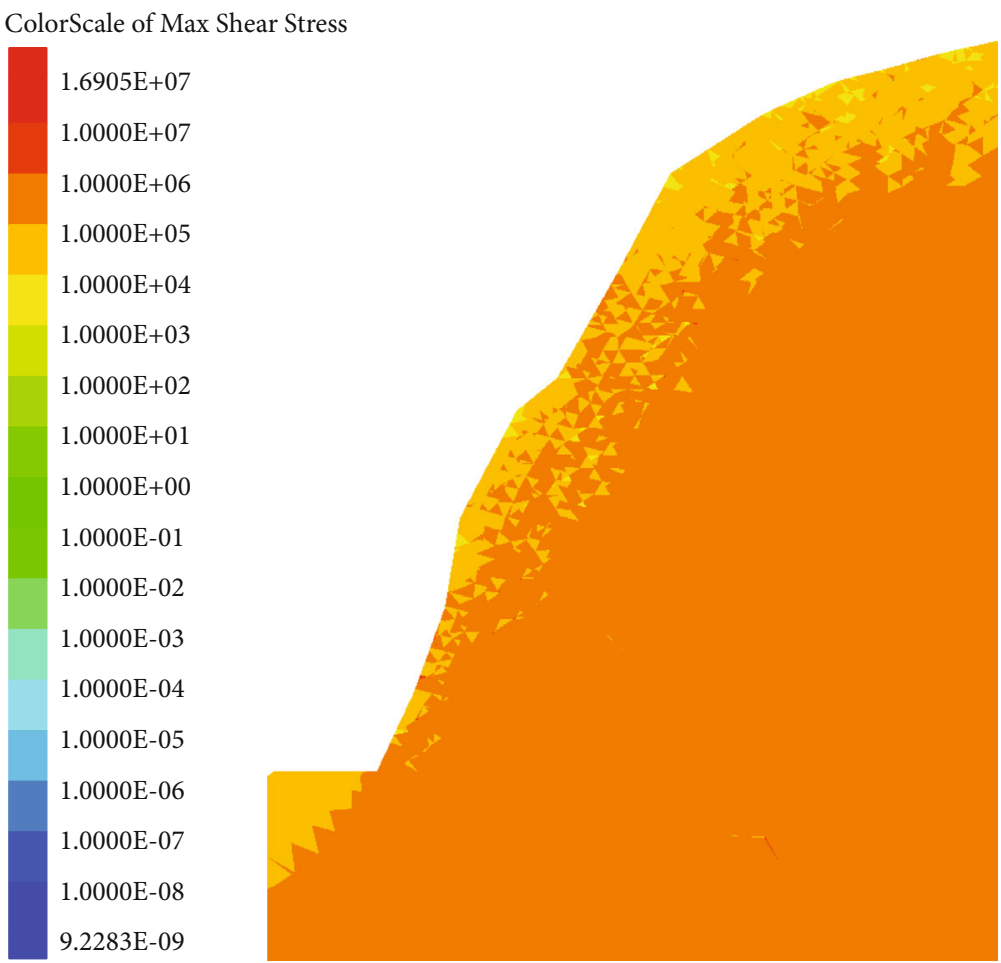

(b) 15 times

Figure 3: Continued. 


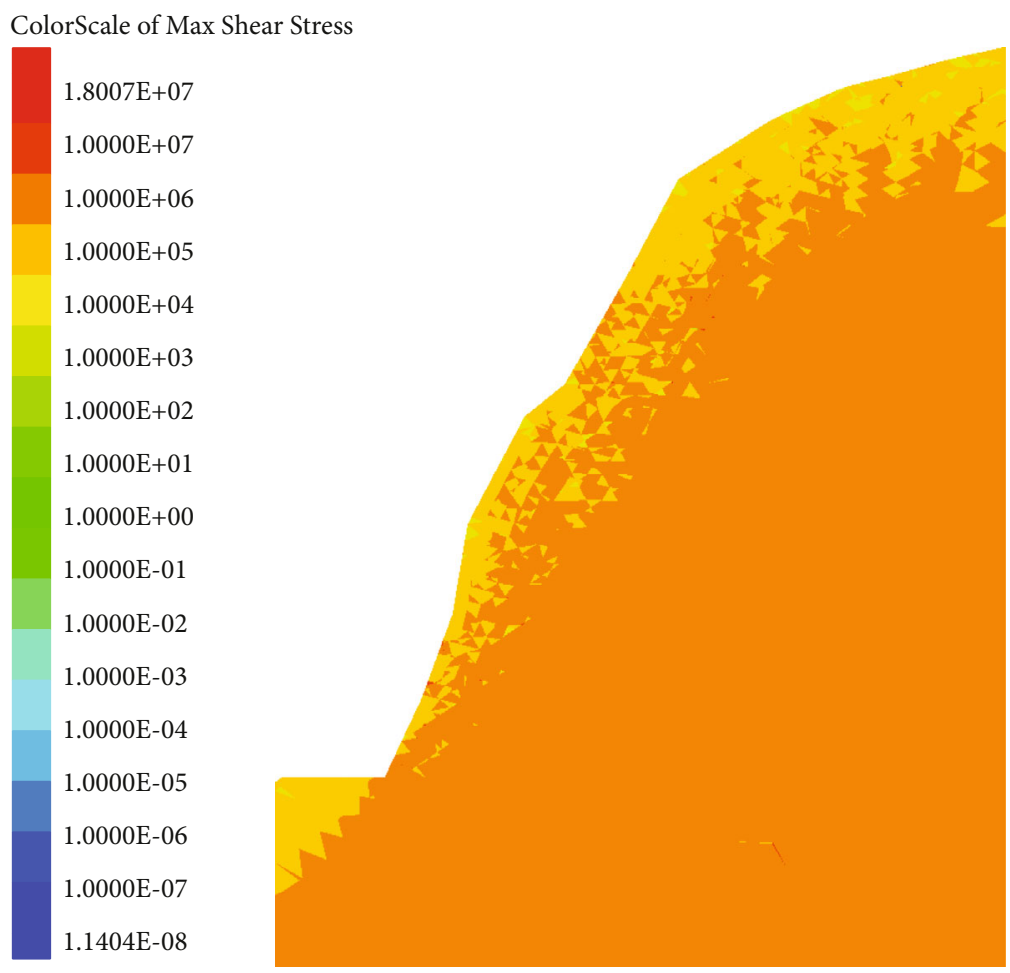

(c) 30 times

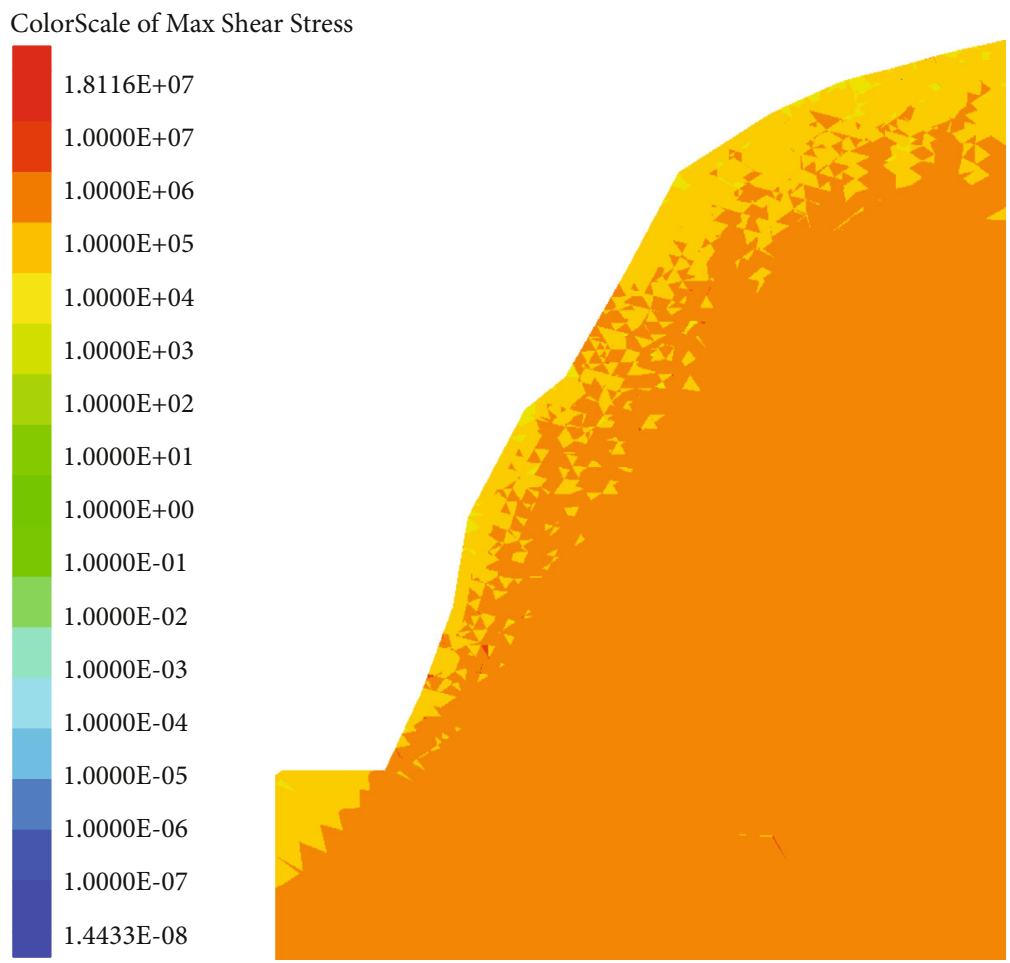

(d) 50 times

FIGURE 3: Max-shear stress distribution of the typical rocky slope.

section of the Tianshan Road has fallen blocks year-round. The weathering thickness of the slope is about $10 \mathrm{~m}$. The dominant structural planes make the rock mass more fragmented with a block-to-fragmental structure. With the combination of discontinuities and the free face, it is prone to slide along the structural planes under the self-weight and external dynamics.

The freezing conditions are the main external forces for the slope failure. The study area is in snowy weather from January to March. In this case, the rainfall and glacier snow 


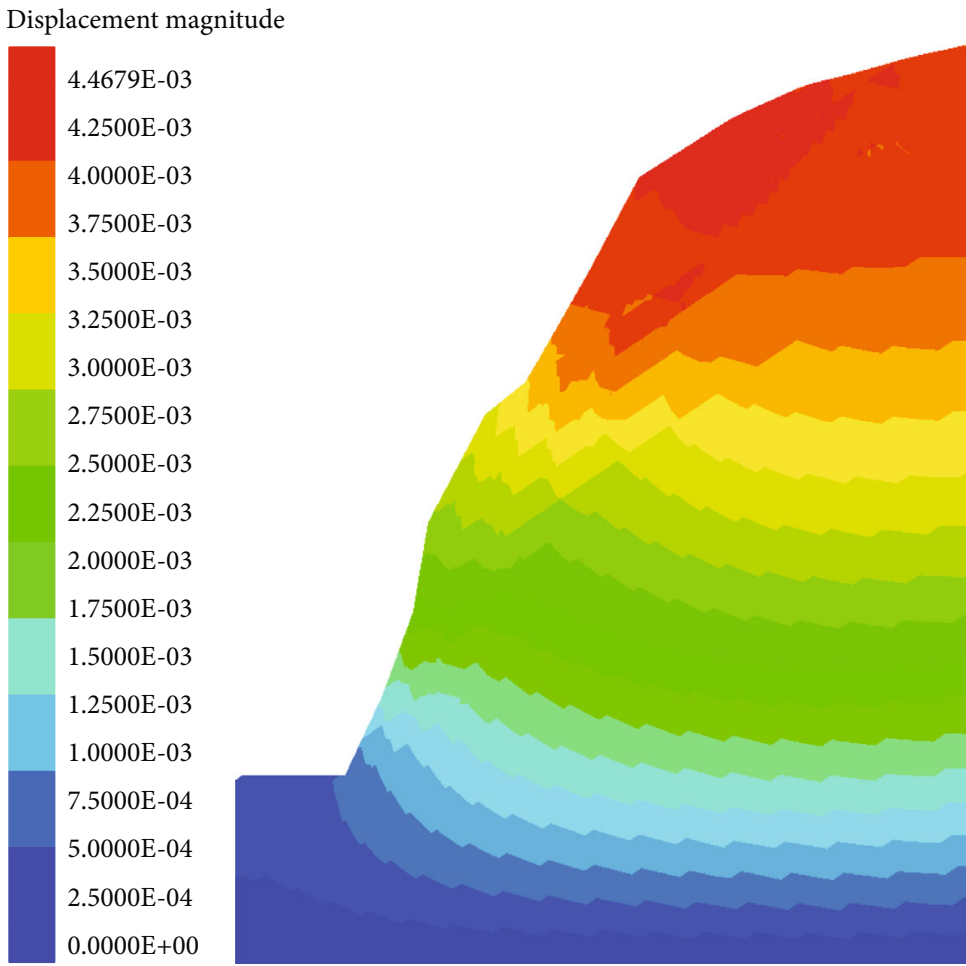

(a) 0 times

Displacement magnitude

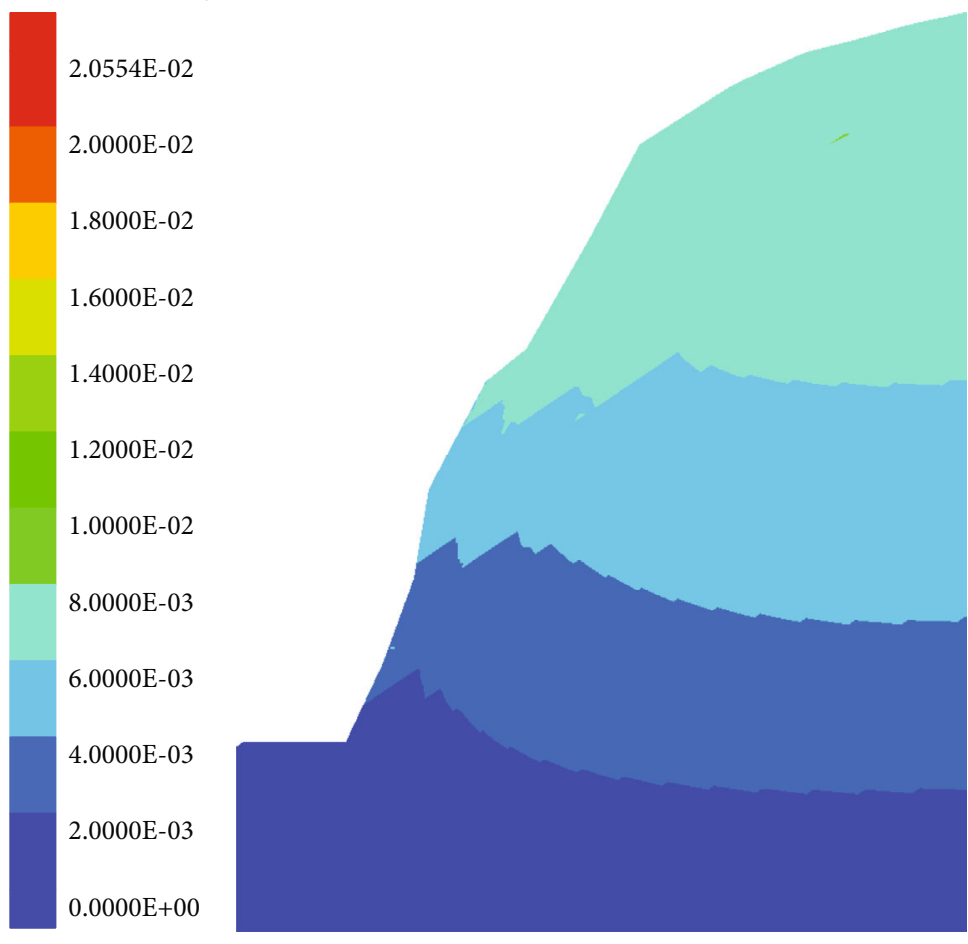

(b) 15 times

Figure 4: Continued. 


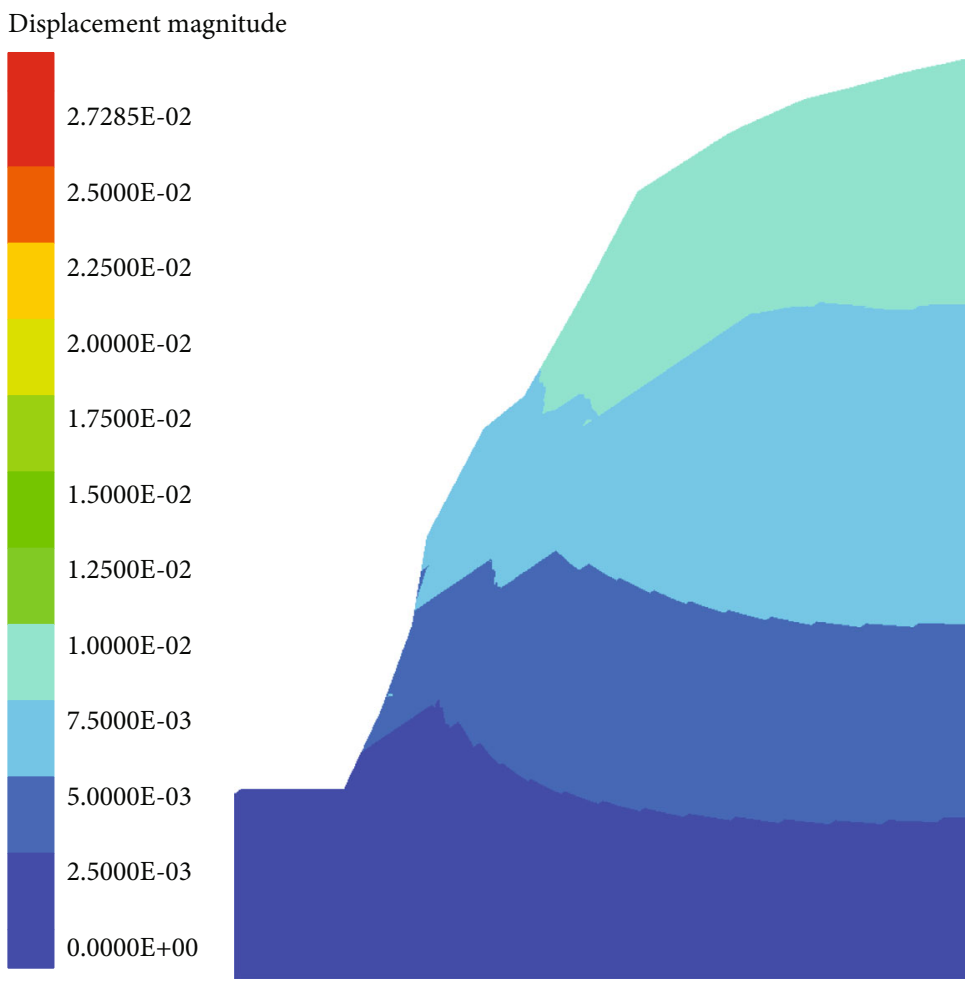

(c) 30 times

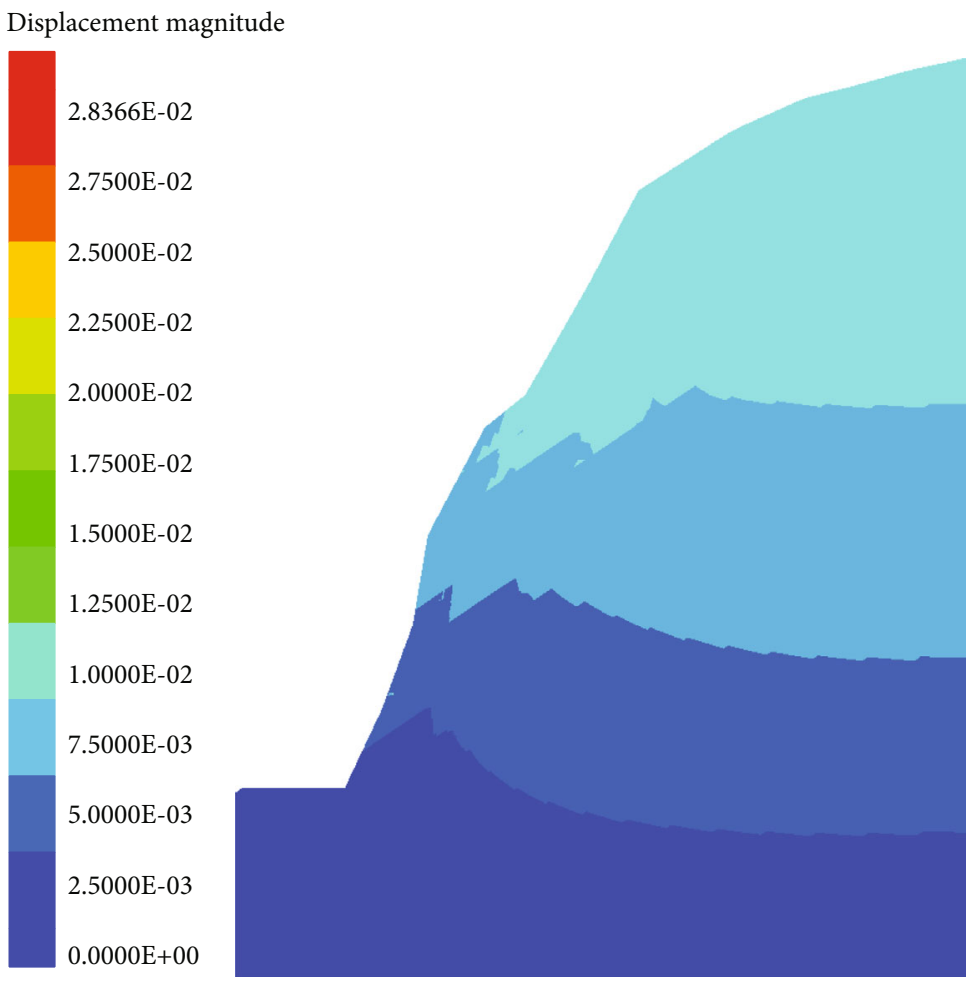

(d) 50 times

Figure 4: Displacement distribution of the typical rocky slope.

melting make water enter the joints network of the rocky slope, which freeze into ice in winter, expand the volume, generate ice splitting force, and push the rock mass. Meanwhile, the rock mass is subjected to the FTC of seasonal reciprocation and the temperature difference between day and night, causing the cracks to expand and the mechanical properties of the rock mass to reduce. Taking one year as a period, the deformation of the rock mass gradually increases. 

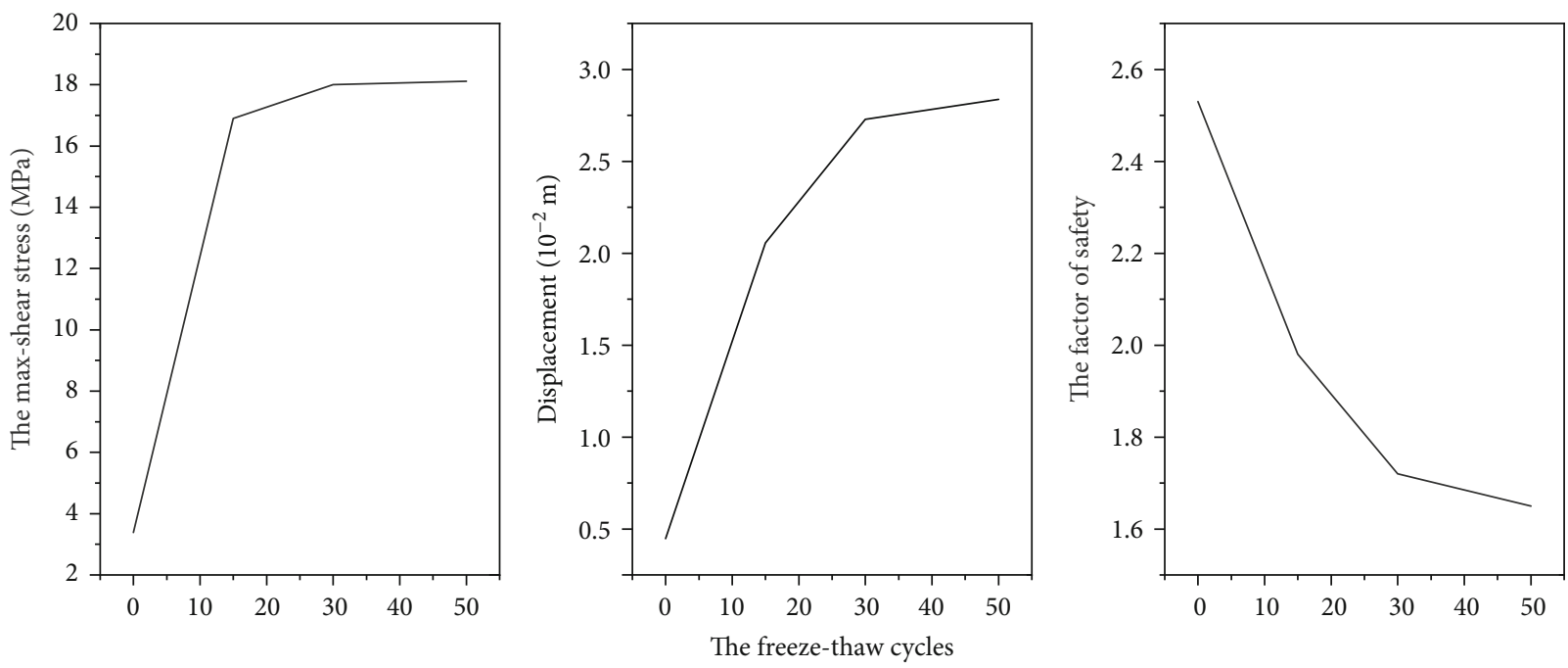

FIgURE 5: The mechanic features of the typical rocky slope under different FTC.

In summary, the failure mechanism of the rocky slope can be determined to the excavation of highway makes the leading-edge to form the slipping space, and the layer of the down-dip slope is cut by the antidip structural planes to form dangerous rock mass. Then, under the action of the internal and external forces, the sliding-cracking deformation is generated. After instability, it slips to the free face, causing a typical sliding-type collapse.

\section{Methods}

Based on the field investigation, 3DEC is used to simulate the large deformations of block systems $[16,17]$. The typical section was divided into two areas ([3,18]; Figure 2$)$. The mechanical parameters of rock mass and structural planes in area I are changing with the FTC. And area II is defined as the nonfreeze-thaw-affected zone. In 3DEC, the blocks and the structural planes are set to the Mohr-Coulomb model. The mechanical parameters of the rocks and structural planes in each area are comprehensively selected through field survey and indoor test results ([19]; Tables 1 and 2).

After the parameters assignments of all the blocks and structural planes, the fixed velocity boundary conditions and load conditions are applied to the numerical model. The left, right, and bottom boundaries of the model are fixed, and the upper part of the model has a free boundary. The times of FTC are taken as the driven parameter, and the self-weight is considered in the load process. When the maximum unbalanced force of the node approaches zero or is relatively small compared with the total force initially applied, the model is taken as a state of equilibrium.

\section{Results}

The analysis of 0 times, 15 times, 30 times, and 50 times of FTC is simulated for the typical rocky slope. And the distri-

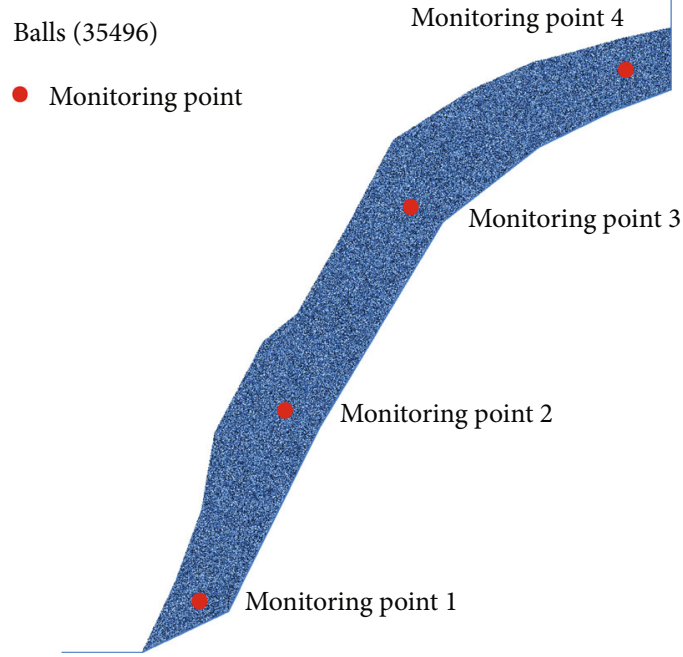

Figure 6: A dynamic simulation model of the typical rocky slope.

bution of max-shear stress (Figure 3) and displacement (Figure 4) is obtained.

After 15 times of the FTC, a stress concentration zone appeared along the structural planes in the freeze-thaw affected area. With the increase of FTC, the concentration distribution of the max-shear stress in the freeze-thaw affected area gradually expands. After 50 times of the FTC, a slipping zone is formed and basically penetrated.

Under the action of the FTC, the maximum displacement of the slope has increased from $4.468 \mathrm{~mm}$ to $20.554 \mathrm{~mm}$ after 15 times of the FTC. After the 50 times of the FTC, the maximum displacement increased to $28.366 \mathrm{~mm}$, and the factor of safety was reduced from 2.56 to 1.64 , which shows that the deformation of the slope will increase and the stability of the slope will decrease.

From the perspective of stability trend (Figure 5), the factor of safety decreases sharply under $0 \sim 15$ times of the 


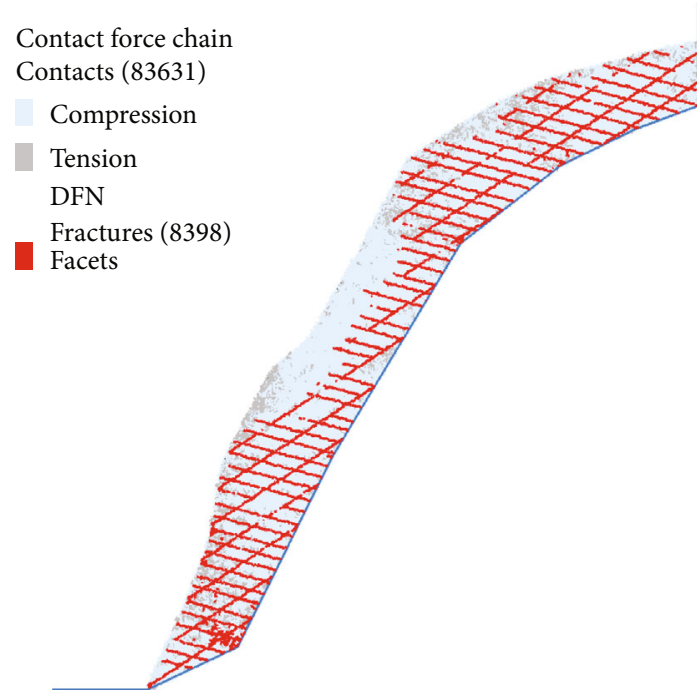

(a) Step 1000

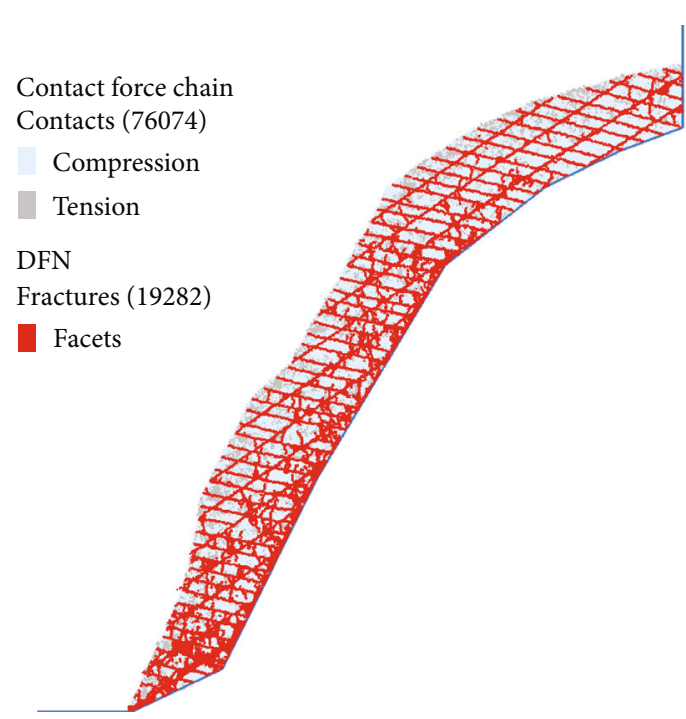

(c) Step 10000

Contact force chain

Contacts (59300)

$\square$ Compression

$\square$ Tension

DFN

Fractures (50561)

Facets

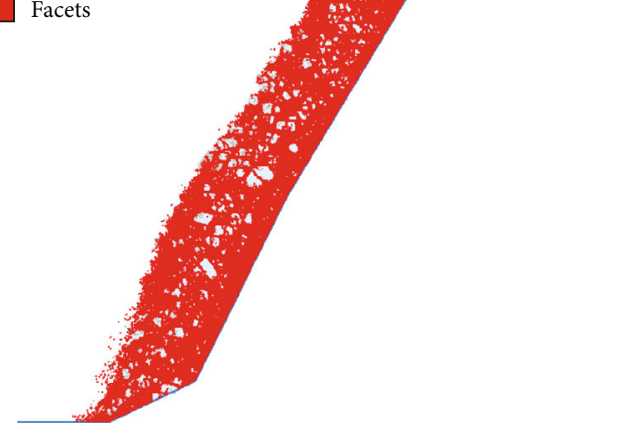

(e) Step 50000

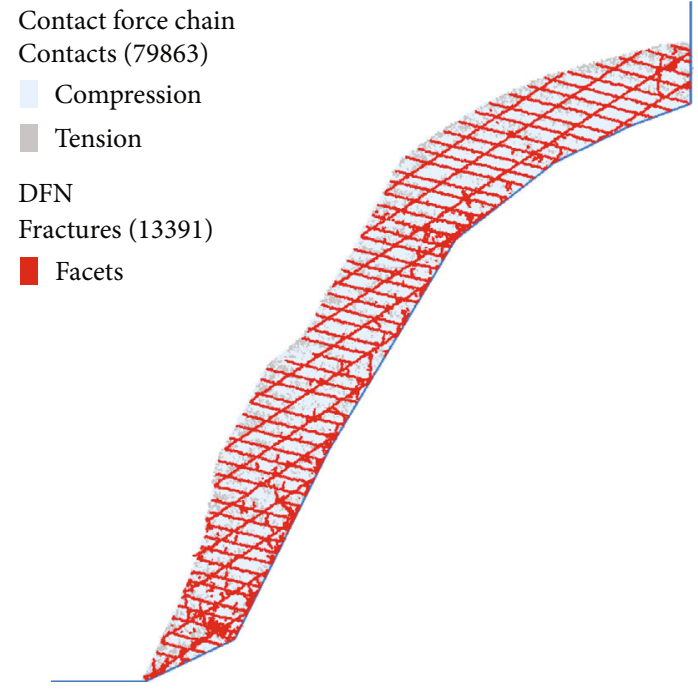

(b) Step 5000

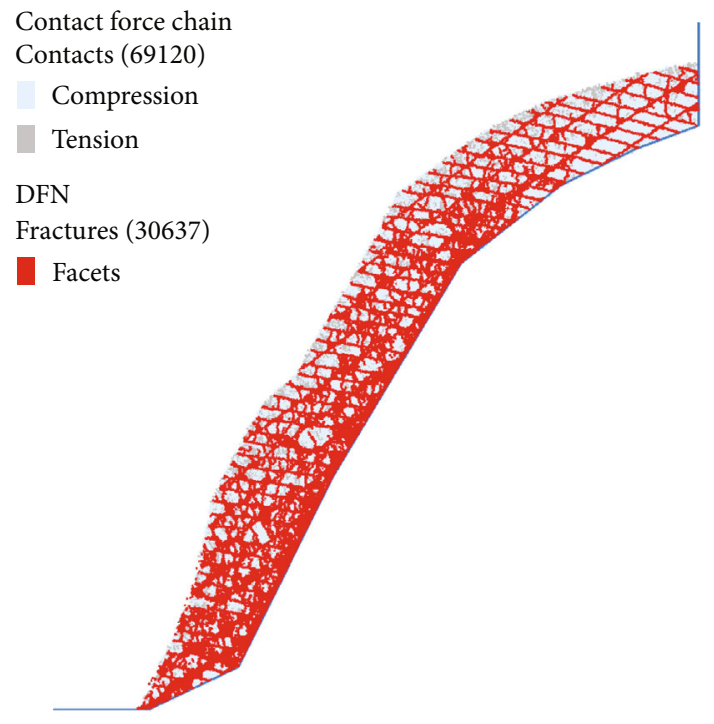

(d) Step 20000

Contact force chain

Contacts (55036)

Compression

Tension

DFN

Fractures (58042)

Facets

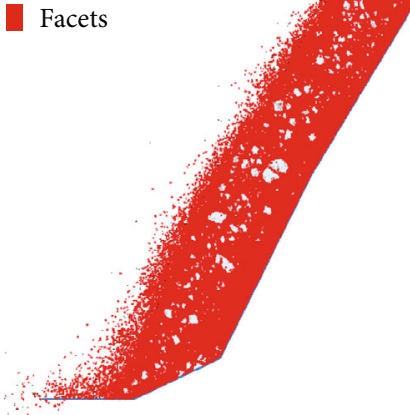

(f) Step 100000

FIgURE 7: Continued. 


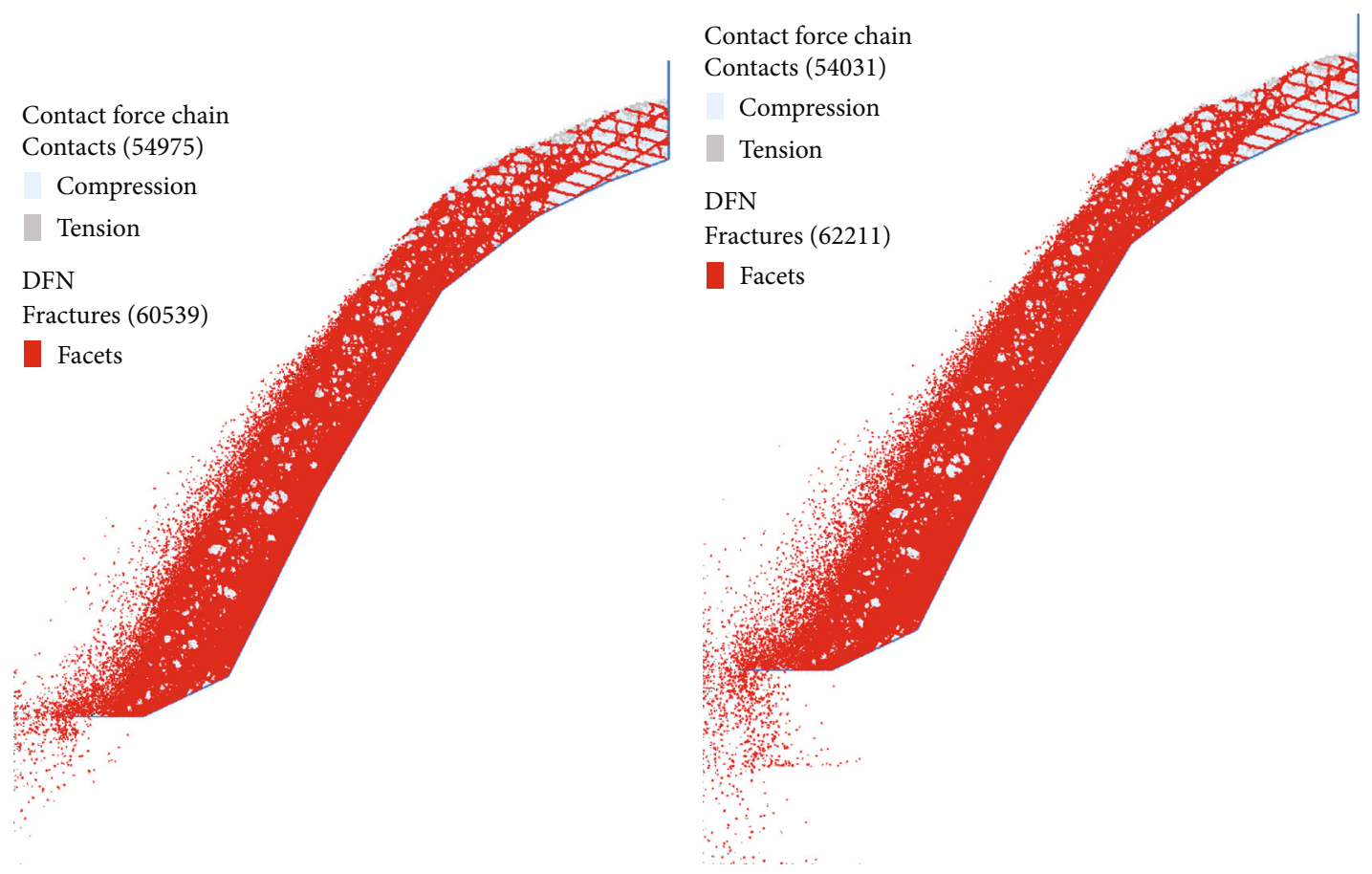

(g) Step 150000

(h) Step 200000

FIGURE 7: The dynamic collapse process of the typical section.

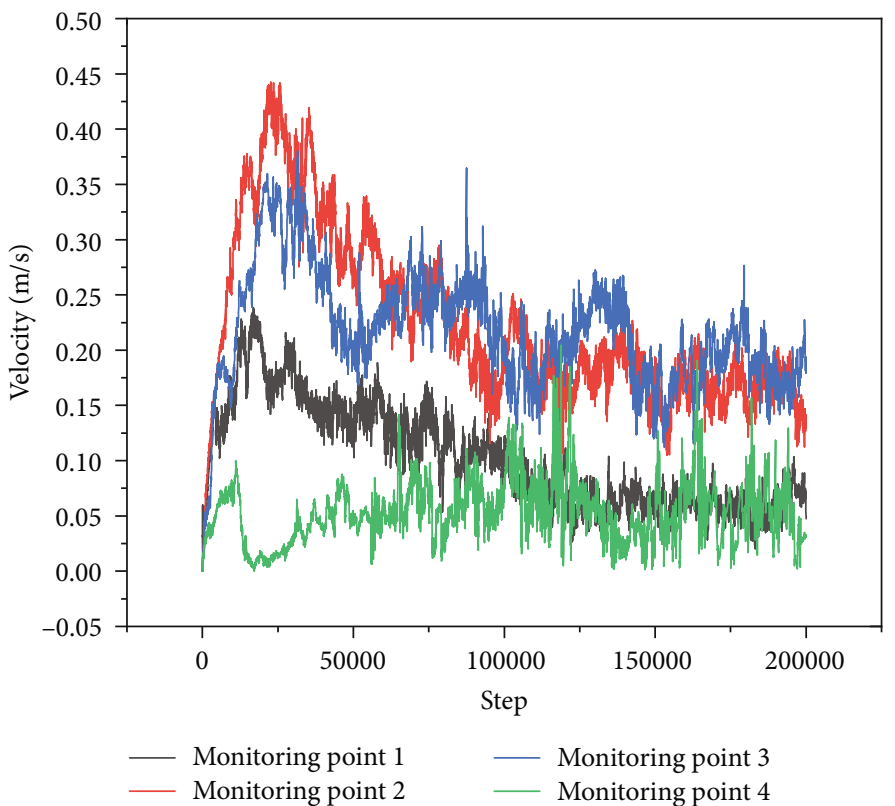

(a)

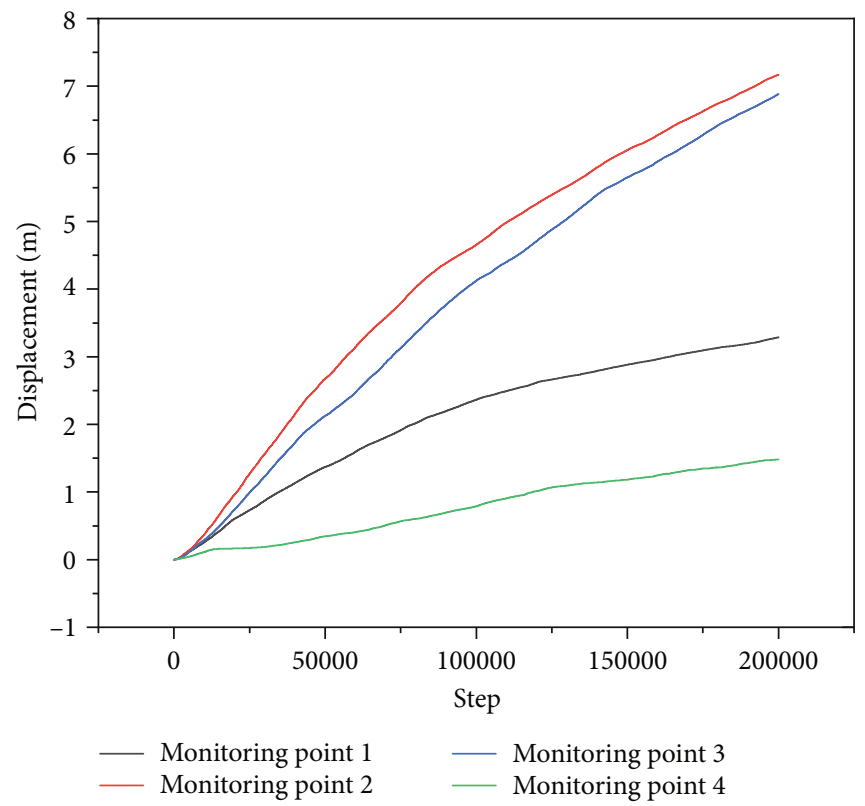

(b)

FIGURE 8: The dynamic characteristics of monitoring points during the collapse process.

FTC, and then the decreasing tendency tends to be gentle after 30 times of the FTC. It can be inferred that the sliding collapse may undergo local instability under the action of the FTC with intense weathering or unloading. Affected by external factors such as heavy rainfall or earthquakes, the slope may be a failure.

\section{Discussions}

According to the previous theoretical analysis, the critical state was predicted by the evolution trend [20]. The related mechanical parameters of the rock mass and discontinuities were determined by the existing test data [21]. Furthermore, 
the microscopic parameters were calibrated according to the macroscopic parameters in the critical state, and the related methods will not be described in detail [22, 23].

A numerical model was established based on the typical section involving 35496 particles (Figure 6). The bedrock without weathering at the trailing edge was simplified as a wall to reduce the amount of calculation. Notably, this simplification of trailing edge may affect the simulation results of the slip rate of the rocky slope, but it can still effectively reveal the whole collapse process. Four monitoring points were placed on the typical section.

The dynamic collapse process of the typical section (Figure 7) led to several conclusions. As the concentration of shear stress in rocky slope, dense cracks expand from the toe to the middle part along the structural planes. The cracks increase and gradually penetrate, forming a gradual cumulative failure, which leads to further collapse of the slope under the action of gravity.

According to the dynamic characteristics of monitoring points (Figure 8), the displacement continues to increase, and the velocity begins to fall after reaching the peak values. Specifically, the peak values of slip velocity and the final slip distance of monitoring point 2 in the leading edge are the largest, while the related values of monitoring point 4 are the smallest. This phenomenon shows that due to the spatial distribution of multiple structural planes and the interaction between the rock fragments, the movement characteristics of the particles have a certain randomness during the failure process. Moreover, the sliding space at the leading edge is limited, and the sliding inclination angle of the trailing edge is small. As a result, there is no long-distance migration, and the in situ accumulation phenomenon of the slope is obvious after slope failure. Even so, the sliding failure of the rocky slope would still cause great damage to Tianshan Road.

The dynamic characteristics of monitoring points are consistent with the data monitored by the Zhenziyan collapse [24], which shows that the numerical simulations are effective.

\section{Conclusions}

Driven by the times of FTC, the mechanical parameters of the rock mass and structural planes were reduced. And the numerical calculations of DEM were used to reveal the disaster-causing effect of the freezing and weathering environment in the alpine area.

Specifically, as the increase of FTC, the structural planes and internal microcracks of the rock mass would expand under the action of frost heave force. Moreover, the physical and mechanical properties of the rock mass on the surface are further deteriorated, leading to a gradual decrease in slope stability.

The dynamic collapse results show that the cracks gradually extend from the toe to the middle part of the rocky slope along the structural planes. The cracks continue to increase and gradually penetrate, forming a progressive failure, which causes further collapse of the slope under the action of gravity. Due to the spatial distribution of multiple structural planes and the interaction between rock frag- ments, the movement characteristics of rock masses have a certain degree of randomness in the collapse process. And the sliding failure of the rocky slope will cause great damage to Tianshan Road. Therefore, it is necessary to strengthen the monitoring of the rocky slope of Tianshan Road. In this case, the real-time deformation and mechanical state can be obtained, and the threat of landslide can be prevented.

\section{Data Availability}

The data used to support the findings of this study are available from the corresponding author upon request.

\section{Conflicts of Interest}

The authors declare that they have no conflicts of interest.

\section{Acknowledgments}

This study was supported by the National Natural Science Foundation of China (52008058 and 52108299).

\section{References}

[1] J. Charvet, L. S. Shu, S. Laurent-Charvet et al., "Palaeozoic tectonic evolution of the Tianshan belt, NW China," Science China-Earth Sciences, vol. 54, no. 2, pp. 166-184, 2011.

[2] F. H. Chen, J. Jia, J. H. Chen et al., "A persistent Holocene wetting trend in arid central Asia, with wettest conditions in the late Holocene, revealed by multi-proxy analyses of loesspaleosol sequences in Xinjiang, China," Quaternary Science Reviews, vol. 146, pp. 134-146, 2016.

[3] J. Q. Mu, The Rock Degradation Damage Characteristics and the Disaster-Causing Effects under the Cyclic FreezeThaw Action, Chengdu University of Technology, 2013, (in Chinese).

[4] Y. Wang, B. Zhang, B. Li, and C. H. Li, "A strain-based fatigue damage model for naturally fractured marble subjected to freeze-thaw and uniaxial cyclic loads," International Journal of Damage Mechanics, 2021.

[5] İ. İnce and M. Fener, "A prediction model for uniaxial compressive strength of deteriorated pyroclastic rocks due to freeze-thaw cycle," Journal of African Earth Sciences, vol. 120, pp. 134-140, 2016.

[6] D. M. Gu, H. L. Liu, X. C. Gao, D. Huang, and W. G. Zhang, "Influence of Cyclic Wettingâ-"Drying on the Shear Strength of Limestone with a Soft Interlayer"," Rock Mechanics and Rock Engineering, vol. 54, no. 8, pp. 4369-4378, 2021.

[7] S. B. Huang, Q. S. Liu, A. P. Cheng, and Y. Z. Liu, "A statistical damage constitutive model under freeze-thaw and loading for rock and its engineering application," Cold Regions Science and Technology, vol. 145, pp. 142-150, 2018.

[8] M. Li, Y. Song, and F. Chen, "Analysis on stability of slope in a typical cold region based on thermo-mechanical coupling," Bulgarian Chemical Communications, vol. 48, pp. 96-103, 2016.

[9] J. W. Zhou, P. Cui, and M. H. Hao, "Comprehensive analyses of the initiation and entrainment processes of the 2000 Yigong catastrophic landslide in Tibet, China," Landslides, vol. 13, no. 1, pp. 39-54, 2016. 
[10] X. D. Luo, N. Jiang, X. Y. Fan, N. F. Mei, and H. Luo, "Effects of freeze-thaw on the determination and application of parameters of slope rock mass in cold regions," Cold Regions Science and Technology, vol. 110, pp. 32-37, 2015.

[11] L. Q. Wang, Y. P. Yin, B. L. Huang, Z. H. Zhang, P. Zhao, and Y. J. Wei, "A study of the treatment of a dangerous thick submerged rock mass in the three gorges reservoir area," Bulletin of Engineering Geology and the Environment, vol. 79, no. 5, pp. 2579-2590, 2020.

[12] P. P. Guo, X. N. Gong, and Y. X. Wang, "Displacement and force analyses of braced structure of deep excavation considering unsymmetrical surcharge effect," Computers and Geotechnics, vol. 113, p. 103102, 2019.

[13] P. P. Guo, X. N. Gong, Y. X. Wang, H. Lin, and Y. L. Zhao, "Minimum cover depth estimation for underwater shield tunnels," Tunnelling and Underground Space Technology, vol. 115, p. 104027, 2021.

[14] Y. Wang, Y. F. Yi, C. H. Li, and J. Q. Han, "Anisotropic fracture and energy characteristics of a Tibet marble exposed to multi-level constant-amplitude (MLCA) cyclic loads: a lab-scale testing," Engineering Fracture Mechanics, vol. 244, p. 107550, 2021.

[15] M. Xu, S. C. Kang, H. Wu, and X. Yuan, "Detection of spatiotemporal variability of air temperature and precipitation based on long-term meteorological station observations over Tianshan Mountains, Central Asia," Atmospheric Research, vol. 203, pp. 141-163, 2018.

[16] L. Q. Wang, Y. P. Yin, C. Y. Zhou, B. L. Huang, and W. P. Wang, "Damage evolution of hydraulically coupled Jianchuandong dangerous rock mass," Landslides, vol. 17, no. 5, pp. 1083-1090, 2020.

[17] L. Q. Wang, B. L. Huang, Z. H. Zhang, Z. W. Dai, P. Zhao, and M. J. Hu, "The analysis of slippage failure of the HuangNanBei slope under dry-wet cycles in the three gorges reservoir region, China," Geomatics, Natural Hazards and Risk, vol. 11, no. 1, pp. 1233-1249, 2020.

[18] Y. Wang, W. K. Feng, H. J. Wang, C. H. Li, and Z. Q. Hou, "Rock bridge fracturing characteristics in granite induced by freeze-thaw and uniaxial deformation revealed by $\mathrm{AE}$ monitoring and post-test CT scanning," Cold Regions Science and Technology, vol. 177, p. 103115, 2020.

[19] J. Q. Mu, X. J. Pei, Y. Huang, and W. K. Min, “Experimental research on mechanical characteristics of rock with cycles of freezing-thawing action," Journal of Engineering Geology., vol. 21, no. 1, pp. 103-108, 2013.

[20] J. J. Zhao, X. Wan, Y. B. Shi, J. B. Wei, and M. L. Lee, "Deformation behavior of mining beneath flat and sloping terrains in mountainous areas," Geofluids, vol. 2021, 16 pages, 2021.

[21] P. A. Cundall, A Computer Model for Simulating Progressive Large Scale Movements in Blocky Rock Systems, Proceedings of the symposium of the International Society for Rock Mechanics, Society for Rock Mechanics (ISRM), France, 1971.

[22] D. O. Potyondy, “The bonded-particle model as a tool for rock mechanics research and application: current trends and future directions," Geosystem Engineering, vol. 18, no. 1, pp. 1-28, 2015.
[23] L. Q. Wang, Y. P. Yin, B. L. Huang, and Z. W. Dai, "Damage evolution and stability analysis of the Jianchuandong dangerous rock mass in the three gorges reservoir area," Engineering Geology, vol. 265, p. 105439, 2019.

[24] K. He, C. L. Chen, and B. Li, "Case study of a rockfall in Chongqing, China: movement characteristics of the initial failure process of a tower-shaped rock mass," Bulletin of Engineering Geology and the Environment, vol. 78, no. 5, pp. 3295-3303, 2019. 